\title{
Synthesis, Characterization, Swelling Studies and Dye Removal of Chemically Crosslinked Acrylic Acid/Acrylamide/N,N-Dimethyl Acrylamide Hydrogels
}

\author{
Ahmed Galal Ibrahim, Farag Abdel Hai, Hamada Abdel Wahab, Hamza Mahmoud \\ Department of Chemistry, Faculty of Science, Al-Azhar University, Cairo, Egypt \\ Email address: \\ ahmed_polytech@yahoo.com (A. G. Ibrahim), faragabdelhai@yahoo.com (F. A. Hai), \\ hamada19982000@hotmail.com (H. Abd El-Wahab), hamzamahmoudahmed@yahoo.com (H. Mahmoud)

\section{To cite this article:} \\ Ahmed Galal Ibrahim, Farag Abdel Hai, Hamada Abdel Wahab, Hamza Mahmoud. Synthesis, Characterization, Swelling Studies and Dye \\ Removal of Chemically Crosslinked Acrylic Acid/Acrylamide/N,N-Dimethyl Acrylamide Hydrogels. American Journal of Applied \\ Chemistry. Vol. 4, No. 6, 2016, pp. 221-234. doi: 10.11648/j.ajac.20160406.12
}

Received: November 6, 2016; Accepted: November 24, 2016; Published: December 23, 2016

\begin{abstract}
Polymeric hydrogels of acrylic acid (AA), acrylamide (AAm) and N,N-Dimethylacrylamide (DMAm) were prepared by free-radical polymerization at $70^{\circ} \mathrm{C}$ in methanol, using allylpentaerythritol (APE) as a multifunctional crosslinker and benzoyl peroxide (BPO) as an initiator. The effects of DMAm concentration and variation of pH solutions on the swelling behavior of polymers were investigated. Also AA/AAm/DMAm hydrogel was used in experiments on adsorption of a water soluble monovalent cationic dye such as Basic Blue 9 (BB-9; Methylene blue). FT-IR results confirmed the Structural features of the obtained hydrogels. Results from SEM observation showed a three dimensional porous structure of the hydrogels. Thermogravimetric analysis (TGA) of hydrogels was performed to investigate the thermal properties. The swelling results showed an increase of the swelling of AA/AAm/DMAm hydrogels as the content of DMAm increases in the hydrogel. The swelling percentage and swelling kinetics parameters such as initial swelling rate and swelling rate constant were determined. It was also shown that the swelling of hydrogels increased with the increase of $\mathrm{pH}$ and the maximum extent was reached at $\mathrm{pH}$ 8 in all compositions. The uptake of BB-9 to AA/AAm/DMAm hydrogel is studied by batch adsorption technique at $25^{\circ} \mathrm{C}$. The hydrogel in the dye solution showed coloration. Kinetics and isotherms of dye adsorption were also studied. It was found that the adsorption kinetics of hydrogels followed a pseudo-second-order model. Equilibrium isotherms were analyzed using the Langmuir and Freundlich isotherms. It was seen that the Freundlich model fits the adsorption data better than the Langmuir model.
\end{abstract}

Keywords: Hydrogel, Swelling, Dye Removal, Cationic Dye, Adsorption, Kinetics, Isotherms, N, N-Dimethylacrylamide

\section{Introduction}

The use of dyes in industries like textile, dying, printing, cosmetics, food coloring, papermaking, etc. can generate colored effluents. Dyes usually have a synthetic origin and complex aromatic molecular structures which are more stable and more difficult to biodegrade [1]. Discharging of dyes which are very toxic into water resources even in a small amount can cause serious ecological problems. Dyes can also cause allergic dermatitis and skin irritation. Some of them have been reported to be carcinogenic and mutagenic for aquatic organisms and humans [2-4]. Therefore, dye pollutionin water stream is a major environmental problem.
Methylene blue is the most commonly used substance for dying cotton, wood and silk. It can cause eye burns which may be responsible for permanent injury to the eyes of humans and animals. On inhalation, it can give rise to short periods of rapid or difficult breathing while ingestion through the mouth produces a burning sensation and may cause nausea, vomiting, profuse sweating, mental confusion and methemoglobinemia [5].

The methods for removing dyes from industrial colored wastewaters could require many processes such as coagulation and flocculation [6], membrane separation [7], oxidation or ozonation [8,9], electro-coagulation [10] and adsorption [11]. Among these methods, adsorption is 
generally preferred due to high efficiency, easy handling and availability of different adsorbents [12].

Nowadays, there is a great interest in the development of new adsorbents having high adsorption capacity and fast adsorption rate for wastewater treatment. Among the various adsorbents, hydrogels gained much attention in recent years. Hydrogels possessing different functional groups have been investigated in the preceding literature for this purpose [13$16]$.

Hydrogels are composed of hydrophilic homopolymer or copolymer network and can swell in the presence of water. Chemical cross-links (covalent bonds) or physical junctions (e.g., secondary forces, crystallite formation and chain entanglements) provide the hydrogels unique swelling behavior and three-dimensional structure [17, 18]. These materials are of great interest due to their promising applications such as heavy metal adsorption $[19,20]$, wound dressing [21], superabsorbent [22, 23], adsorbent for dye removal [24] and drug-delivery systems [25, 26]. Many attempts have been made to develop new hydrogels through methods such as irradiation and chemically crosslinking. Hydrogels can be prepared by simultaneous copolymerization and crosslinking of one or more monofunctional and one multifunctional monomer or by crosslinking of a homopolymer or copolymer in solution. In recent years, considerable researches have been done on the characterization and swelling behaviour of synthetic hydrogels prepared by simultaneous free radical copolymerization and crosslinking in the presence of an initiator and a crosslinking agent [27-32]. They can also show stimuli-responsive properties to the various external parameters such as temperature, $\mathrm{pH}$, solvent composition and salt composition depending on the type of functional groups in the structure $[33,34]$.

The present work was aimed to synthesize polymeric hydrogels based on N,N-Dimethylacrylamide (DMAm) with acrylic acid (AA) and acrylamide (AAm) using allylpentaerythritol (APE) as crosslinking agent. The effect of DMAm monomer on the dynamic and equilibrium swelling behavior of hydrogels in distilled water and in buffers of $\mathrm{pH} 4$ and 8 at $25 \pm 0.1^{\circ} \mathrm{C}$ was investigated. In this work, it has been aimed to study a convenient method for removing the water soluble monovalent cationic dye such as Basic Blue 9 (Methylene blue) from aqueous solutions by adsorption on novel polymeric adsorbent such as AA/AAm/DMAm hydrogels. The adsorption kinetics and isotherms for BB-9 dye onto the hydrogels were also studied.

\section{Experimental}

\subsection{Materials}

The Acrylic acid (AA), Acrylamide (AAm) and N,NDimethylacrylamide (DMAm) were produced by SigmaAldrich Company Ltd based in UK. Allylpentaerythritol (APE) and Benzoyl peroxide (BPO) were supplied by Merck. Basic Blue 9 (Methylene blue; MB) spectroscopic grades used in sorption studies were purchased from Fluka (USA). The chemical structures of the monomers employed in polymerization as well as the structure of BB-9 are shown in Figure 1. Double distilled water was used for polymerizations, swelling and adsorption experiments.

\subsection{Synthesis of Hydrogels}

Hydrogels were prepared by free-radical crosslinking polymerization of AA, AAm and DMAm in methanol using BPO as initiator. APE was used as crosslinking agent. $2.5 \mathrm{~g}$ of acrylamide, $2.5 \mathrm{~g}$ of acrylic acid and $50 \mathrm{mg}$ of APE were dissolved in $20 \mathrm{~mL}$ methanol, and then $0.2,0.4,0.6,0.8,1 \mathrm{~g}$ of DMAm were added to the alcoholic solution of AA/AAm (Table 1). The polymerization was initiated by the addition of $1 \mathrm{~mL}$ of $5 \%(\mathrm{w} / \mathrm{v})$ solution of BPO in methanol. After bubbling nitrogen for $15 \mathrm{~min}$, the reaction was carried out in $100 \mathrm{ml}$ two-necked round-bottom flask fitted with a reflux condenser and a thermometer. The mixture was kept at $70^{\circ} \mathrm{C}$ for $2 \mathrm{~h}$. The produced samples were washed several times with water to remove the uncrosslinked polymer and unreacted monomers from hydrogels. The extracted gels were dried in vacuum oven at $40^{\circ} \mathrm{C}$ to constant weight and stored in desiccators containing anhydrous calcium chloride, as a desiccant agent, for further use. The produced hydrogels were characterized by FT-IR as well as the thermal properties.<smiles>C=CC(N)=O</smiles>

acrylamide (AAm)<smiles>C=CC(=O)O</smiles>

acrylic acid (AA)<smiles>C=CC(=O)N(C)C</smiles>

$\mathrm{N}, \mathrm{N}-$ Dimethylacrylamide (DMAm)<smiles>CN(C)c1ccc2nc3ccc(N(C)C)cc3[s+]c2c1</smiles>

Methylene blue (BB-9)

Figure 1. Chemical structures of the monomers and the Methylene blue.

Table 1. Feed composition for the prepared hydrogels.

\begin{tabular}{lllllll}
\hline Sample & AA/g & AAm/g & DMAm/g & APE/mg & BPO/mL & Yield \% \\
\hline P1 & 2.5 & 2.5 & 0.2 & 50 & 1 & $>98$ \\
P2 & 2.5 & 2.5 & 0.4 & 50 & 1 & $>98$ \\
P3 & 2.5 & 2.5 & 0.6 & 50 & 1 & $>98$ \\
P4 & 2.5 & 2.5 & 0.8 & 50 & 1 & $>98$ \\
P5 & 2.5 & 2.5 & 1 & 50 & 1 & $>98$ \\
\hline
\end{tabular}

\subsection{Swelling measurements}

The swelling behaviors of weighed dried hydrogel samples were carried out by immersion in distilled water at room temperature. The gels were gently wiped and weighed to determine the water absorbed at various time intervals. The 
Swollen gels were weighed by an electronic balance (SARTORIUS) with an accuracy of $\pm 0.0001 \mathrm{~g}$. The effect of $\mathrm{pH}$ on the swelling properties was studied using buffers of pH 4 and 8. All swelling studies were carried out in $150 \mathrm{~mL}$ of swelling medium. The swelling studies were carried out until equilibrium in swelling was reached. Swelling measurements were done two or three times. The total uncertainly for all experiments ranged from 3 to $5 \%$. The swelling ratio was calculated using the following equation:

$$
\% S=\frac{M_{t}-M_{o}}{M_{o}} \times 100
$$

Where, $M_{t}$ and $M_{o}$ refer to the weight of swollen hydrogel at time $t$ and at time 0 , respectively.

The equilibrium degree of swelling $S_{\text {eq }}$, after hydrogels had swollen to equilibrium in the swelling media was calculated using the following equation:

$$
\% S_{e q}=\frac{M_{e q}-M_{o}}{M_{o}} \times 100
$$

Here, $M_{e q}$ is the mass of the swollen hydrogel sample at equilibrium.

The water absorbed by AA/AAm/DMAm hydrogels is quantitatively represented by the equilibrium water content (EWC) $[35,36]$, where

$$
E W C=\frac{M_{e q}-M_{O}}{M_{e q}}
$$

\subsection{Characterization Techniques}

The Fourier transform infrared (FT-IR) spectra of the prepared hydrogels were recorded on a Nicolet 400D FT-IR spectrometer, using $\mathrm{KBr}$ pellets. Thermal properties were examined using a Simultaneous DSC-TGA (USA) Q600SDT System from TA Instruments. The temperature range covered was $25-600^{\circ} \mathrm{C}$ and the scanning rate $10{ }^{\circ} \mathrm{C} \mathrm{min}{ }^{-1}$, under nitrogen atmosphere. Scanning electron microscopy (SEM) analysis was carried out using SEM Model Quanta 250 FEG (Field Emission Gun) attached with EDX Unit (Energy Dispersive X-ray Analyses), with accelerating voltage $30 \mathrm{~K} . \mathrm{V}$., magnification $14 \mathrm{x}$ up to 1000000 and resolution for Gun.1n. Prior to examination, samples were gold-sputter coated to render them electrically conductive.

\subsection{Adsorption Studies}

\subsubsection{Preparation of the Dye Solution}

Methylene blue ( $\lambda_{\max }: 663 \mathrm{~nm}$, molecular formula: $\mathrm{C}_{16} \mathrm{H}_{18} \mathrm{~N}_{3} \mathrm{SCl}$, nature: basic blue, and molecular weight: 319 ) was used as an adsorbate and was not purified prior to use. An accurately weighed quantity of the dye $(0.1 \mathrm{~g})$ was dissolved in double distilled water to prepare a $100 \mathrm{mg} \mathrm{L}^{-1}$ stock solution. Experimental solutions of various concentrations were prepared by further dilutions of the stock solution. The absorbance of these dilute solutions was measured on a UV-visible spectrophotometer. Standard curves were prepared by plotting the absorbance values against the concentrations.

\subsubsection{Adsorption Experiments}

Prior to the dye adsorption, accurately weighed hydrogels $(12 \mathrm{mg}$ ) were immersed in water for at least $12 \mathrm{~h}$ to achieve the swelling equilibrium. Adsorption experiments were carried out at room temperature, in cylindrical glass vessels, by using batch conditions. In these experiments, the swollen samples of the prepared hydrogels were immersed in MB dye solutions $(10 \mathrm{ml})$ with concentration of $100 \mathrm{mg} / \mathrm{L}$. The amount of residual dye in the solution was determined at regular time using a PERKIN-ELMER UV-Vis spectrophotometer. All of the experiments were performed in triplicate and the average was used in this work. Dependence of adsorption capacities on time was determined and adsorption kinetics was investigated in detail. The influence of $\mathrm{pH}$ on $\mathrm{MB}$ removal was studied by adjusting MB solutions $(100 \mathrm{mg} / \mathrm{L})$ to different $\mathrm{pH}$ values $(3.0,4.0,7.0$ and 8.0) using a $\mathrm{pH}$ meter (DELTA-320).

The amounts of adsorbed dye per unit mass of adsorbent at time $\mathrm{t}\left(Q_{t}, m g g^{-1}\right)$ and at equilibrium $\left(Q_{e}, m g g^{-1}\right)$ were calculated by using the following expressions:

$$
\begin{aligned}
& Q_{t(m g / g)}=\frac{\left(C_{i}-C_{t}\right) V_{(L)}}{m_{(g)}} \\
& Q_{e(m g / g)}=\frac{\left(C_{i}-C_{e}\right) V_{(L)}}{m_{(g)}}
\end{aligned}
$$

Where $C_{i}$ and $C_{e}$ are the initial and equilibrium concentrations of dye $(\mathrm{mg} / \mathrm{L})$, respectively and $C_{t}$ is dye concentration at time $t, V$ is the volume of the solution added $(L)$ and $\mathrm{m}$ is the amount of polymer $(g)$.

\subsubsection{Adsorption Kinetics and Isotherms}

\section{(i) Kinetic Models}

The pseudo first-order and pseudo second-order kinetic models were used to predict the dye adsorption behaviors of the prepared hydrogels. The pseudo-first-order equation is generally suitable for the initial stage of the adsorption, but the pseudo-second-order equation predicts the adsorption behavior over the whole process. The kinetics of adsorption was determined by analyzing the dye adsorbed from aqueous solution at various time intervals, and then fitting the data to the two models. The pseudo first-order rate equation is given as $[37,38]$ :

$$
\ln \left(Q_{e}-Q_{t}\right)=\ln Q_{e 1}-K_{1} t
$$

Where, $Q_{e}$ and $Q_{t}$ are the amounts of adsorbed dyes by the hydrogel at equilibrium $(\mathrm{mg} / \mathrm{g})$ and at contact time $t$, respectively. $Q_{e l}$ and $k_{l}$ show the theoretical equilibrium adsorption and pseudo first-order adsorption rate constant $\left(\mathrm{min}^{-1}\right)$, respectively.

The pseudo second-order kinetic model is given below: $[37,38]$.

$$
\frac{t}{Q_{t}}=\frac{1}{K_{2} Q_{e 2}^{2}}+\frac{t}{Q_{e 2}}
$$

Where $Q_{e 2}$ and $k_{2}$ are the theoretical equilibrium adsorption and pseudo second-order adsorption rate constant $\left(g \mathrm{mg}^{-1} \mathrm{~min}^{-1}\right)$, respectively. 


\section{(ii) Isotherm Models}

The Langmuir and Freundlich isotherms are widely applied to describe the equilibrium adsorption isotherm data. The Langmuir isotherm is based on the hypothesis that uptake occurs on a homogeneous surface by monolayer adsorption, without interaction between the adsorbent and adsorbate [39]. The linear equation can be expressed as

$$
\frac{C_{e}}{Q_{e}}=\frac{1}{K_{L} q_{m}}+\frac{C_{e}}{q_{m}}
$$

Where, $C_{e}$ is the equilibrium concentration of adsorbate $(m g / L) ; Q_{e}$ is the amount of dye adsorbed per gram of the adsorbent at equilibrium $(\mathrm{mg} / \mathrm{g}) ; q_{m}$ is maximum monolayer coverage capacity $(\mathrm{mg} / \mathrm{g})$ and $K_{L}$ is Langmuir isotherm constant $(L / m g)$. In this case, the values of $q_{m}$ and $K_{L}$ are computed from the slope and intercept of the Langmuir plot of $C_{e} / q_{e}$ versus $C_{e}$.
The Freundlich isotherm is generally used to describe the non-ideal adsorption on heterogeneous surfaces, suggesting multilayer adsorption on adsorbent surfaces. The linear form of the Freundlich isotherm [40] is given by the following equation:

$$
\log Q_{e}=\log K_{f}+\frac{1}{n} \log C_{e}
$$

Where, $K_{f}$ is Freundlich isotherm constant $(L / g) ; n$ is related to adsorption intensity; $C_{e}$ is the equilibrium concentration of adsorbate $(\mathrm{mg} / \mathrm{L})$ and $Q_{e}$ is the amount of dye adsorbed per gram of the adsorbent at equilibrium $(\mathrm{mg} / \mathrm{g})$. The constant $K_{f}$ is an approximate indicator of adsorption capacity, while $1 / n$ is a function of the strength of adsorption. The values of $K_{f}$ and $n$ were calculated from the intercept and slope of the plots of $\log Q_{e}$ against $\log C_{e}$. (a)<smiles>O=C(OOC(=O)c1ccccc1)c1ccccc1</smiles>

benzoyl peroxide<smiles>O=C([O-])c1ccccc1</smiles>

Initiator radical [ $\left.1^{\circ}\right]$

(b)<smiles>C=CC(N)=O</smiles>

AAm<smiles>C=CC(=O)O</smiles>

AA<smiles>C=CC(=O)OC</smiles>

DMAm

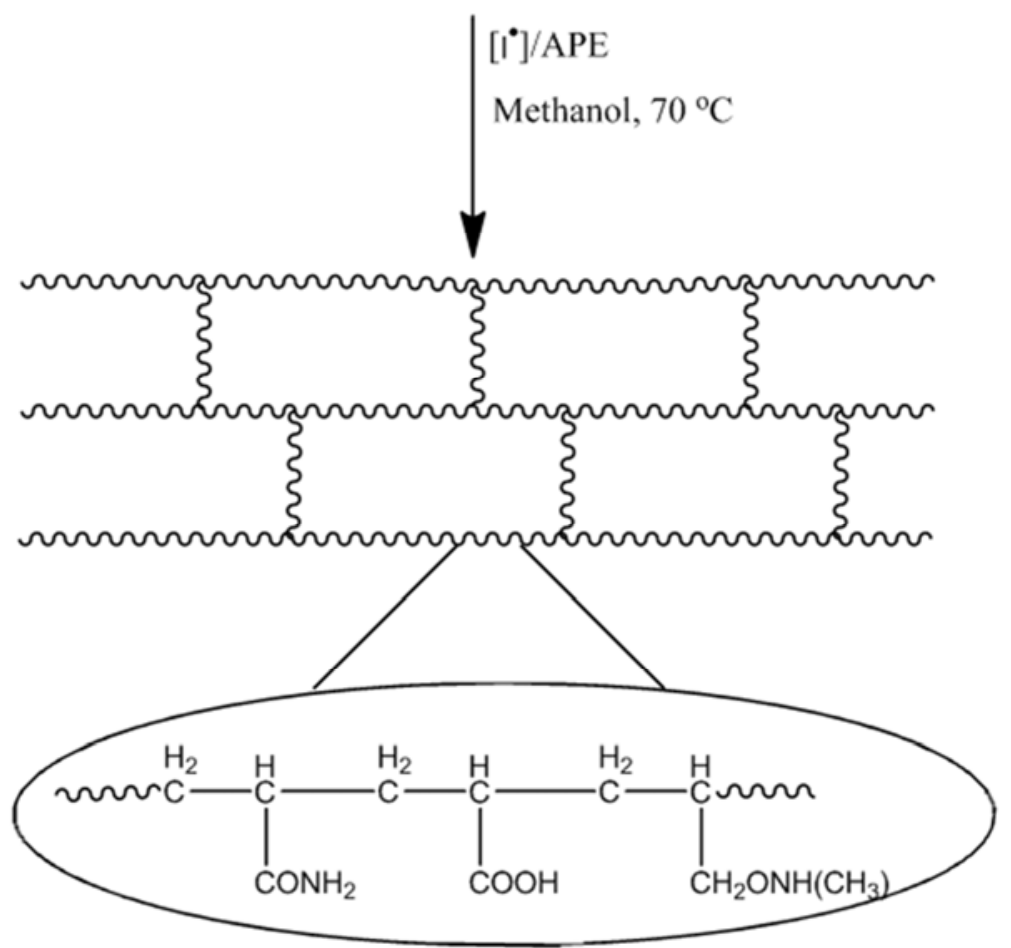

Figure 2. (a) Formation of initiator radicals, (b) Formation of AA/AAm/DMAm hydrogel 


\section{Results and Discussion}

\subsection{Synthesis and FT-IR Analysis of Hydrogels}

In the present investigation, the hydrogel samples were synthesized via crosslinking free radical polymerization of $\mathrm{AA}, \mathrm{AAm}$ and DMAm in a methanol as polymerization medium using APE as a crosslinking agent. The procedure is described in details in the experimental section. The possible step in the polymerization reaction can be explained as follow: Upon heating the reaction mixture primary radicals begin to generate via homolytic decomposition of the BPO (Figure 2a) to produce benzoyl radicals. These radicals rapidly react with the three monomers, i.e., AA, AAm and DMAm or the APE crosslinker molecules to produce the primary radicals. These monomer radicals undergo propagation and termination reaction to form crosslink hydrogels, as shown in Figure $2 b$, that do not dissolve in the reaction medium. Their insolubility is due to the formation of permanent links between the polymeric chains. The presence of functional groups in the prepared hydrogel samples was evaluated via FT-IR spectra as shown in Figure 3. The broad absorption band at $3439 \mathrm{~cm}^{-1}$ is ascribed to the existence of $-\mathrm{OH}$ and $-\mathrm{NH}$ groups [41]. The bands at 2924 and $2855 \mathrm{~cm}^{-1}$ are ascribed to aliphatic $\mathrm{C}-\mathrm{H}$ stretching vibration. The bands at $1652-1684 \mathrm{~cm}^{-1}$ can be attributed to carbonyl groups of acrylamide and carboxylic acid [15, 42]. The band around $1529 \mathrm{~cm}^{-1}$ is ascribed to stretching flexural vibrations of $\mathrm{N}-\mathrm{H}$ group. The characteristic absorption bands around 1245 and $1031 \mathrm{~cm}^{-1}$ are due to the stretching vibration of $\mathrm{N}-\mathrm{CH}_{3}$. The vinyl bands at $1680 \mathrm{~cm}^{-1}$ did not appear in spectra indicating that all monomeric groups are involved in the polymerization reaction $[27,43]$.

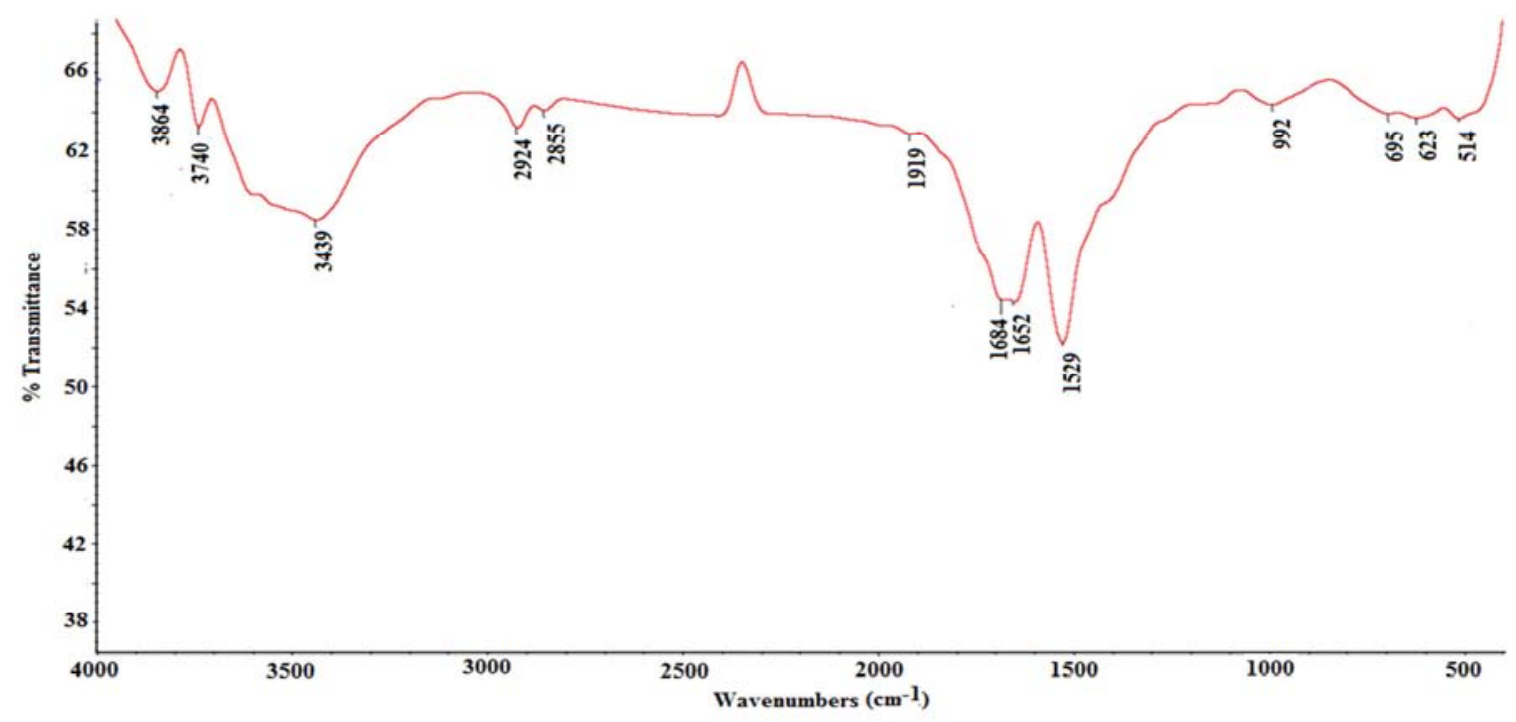

Figure 3. Representative FT-IR spectrum of AA/AAm/DMAm hydrogel

\subsection{Swelling Studies}

The hydrogels were placed in a known amount of distilled water, buffer $\mathrm{pH} 4$ and buffer $\mathrm{pH} 8$ solutions (150 $\mathrm{mL}$ ) and allowed to swell. The initial weight of the gel was compared to the swollen weight. This allows for a transient analysis of the swelling of hydrogel. The weights of the swollen gel were measured at time intervals. The water was absorbed in the gel thus increasing the weight of the gel with time until equilibrium swelling weight is reached. While weighing the gels, care was taken to remove the solvent on the surface, so that only the weight of the water incorporated into the hydrogel was considered. The percentage swelling $(\% \mathrm{~S})$ of the hydrogels in distilled water and in buffers of $\mathrm{pH} 4$ and 8 was calculated from equation (1) (as mentioned in experimental section). The effect of hydrophilic monomer DMAm on the swelling behavior was studied by fixing concentration of AA, AAm and APE while the DMAm was changed to be $0.2,0.4,0.6,0.8$ and $1 \mathrm{~g}$. The dynamic swelling behavior of AA/AAm/DMAm hydrogels in distilled water, buffer of $\mathrm{pH} 4$ and buffer of $\mathrm{pH}$ 8 is shown in Figure 3(a-c). It can be seen that percentage swelling of the hydrogels increases with time until a certain level, when it becomes constant. This value of percentage swelling may be named equilibrium swelling percentage $\left(\% S_{e q}\right)$. The swelling studies were carried out until equilibrium in swelling was reached.

The results in Table 2 showed that, the values of equilibrium swelling of AA/AAm/DMAm hydrogels range from $1757-2984 \%$ in distilled water, $1424-2607 \%$ at $\mathrm{pH} 4$ and $2769-4068 \%$ at $\mathrm{pH} 8$ at different concentrations of DMAm. As shown in Figure 4 the values of the equilibrium swelling of AA/AAm/DMAm hydrogels increase with increasing the concentration of DMAm monomer from 0.2 $\mathrm{g}$ to $1 \mathrm{~g}$. The reason of this is the hydrophilicity of DMAm monomer. The more hydrophilic groups in the AA/AAm/DMAm hydrogels get more swelling and this also the reason that made the values of the equilibrium swelling increase from P1 sample to P5 sample. This is an expected result about swelling of AA/AAm/DMAm hydrogels. 

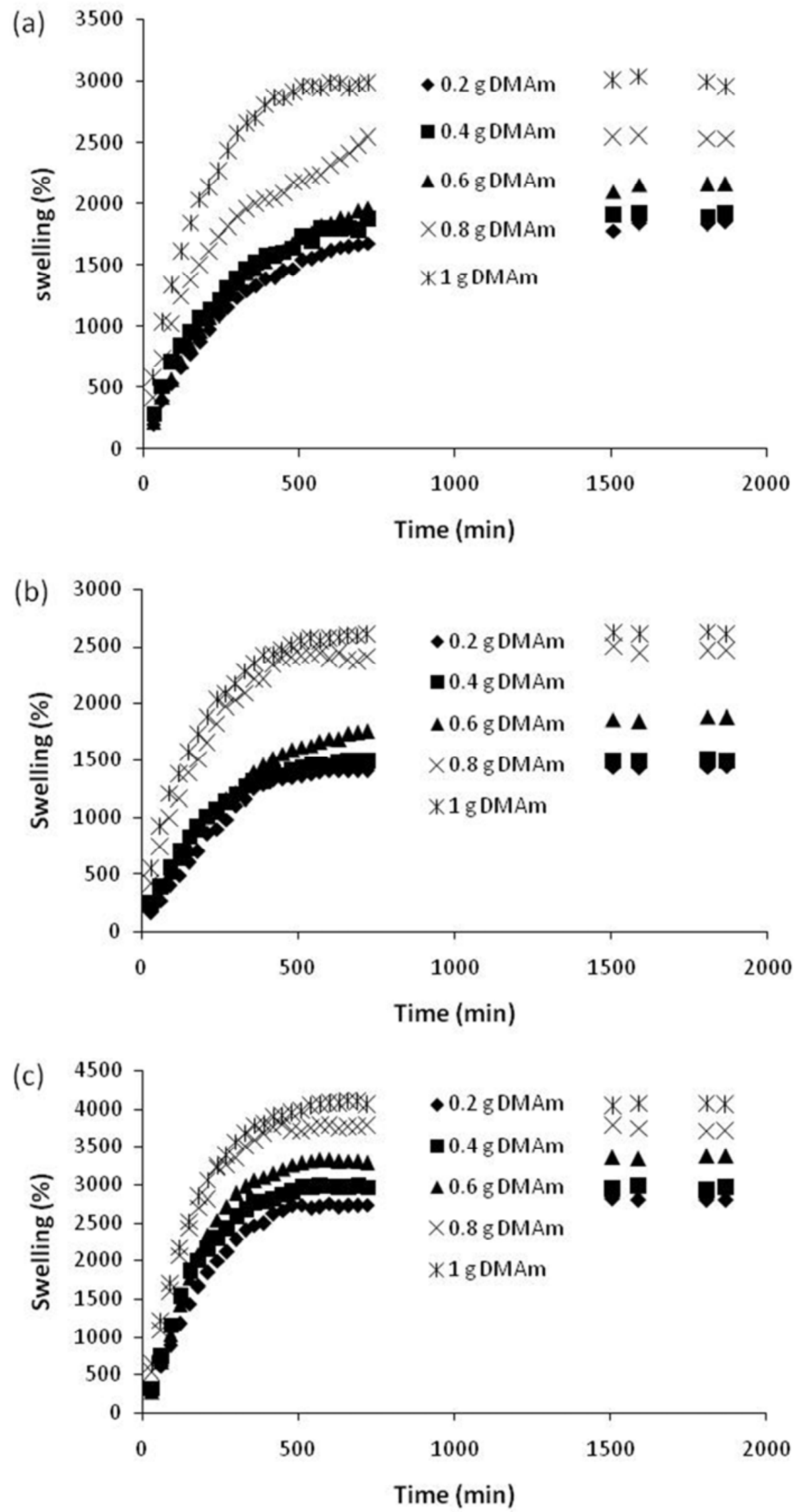

Figure 4. Swelling curves of $A A / A A m / D M A m$ hydrogels in (a) distilled water (b) buffer of $p H=4$ (c) buffer of $p H=8$. 
Table 2. Swelling values of AA/AAm/DMAm hydrogels.

\begin{tabular}{|c|c|c|c|c|c|c|}
\hline \multirow{2}{*}{ Sample } & \multicolumn{3}{|c|}{ Equilibrium swelling $\left(\% \mathrm{~S}_{\mathrm{eq}}\right)$} & \multicolumn{3}{|c|}{$\begin{array}{l}\text { Equilibrium water content } \\
\text { (EWC) }\end{array}$} \\
\hline & DW & $\mathrm{pH}=4$ & $\mathbf{p H}=8$ & DW & $\mathrm{pH}=4$ & $\mathrm{pH}=8$ \\
\hline P1 & 1757 & 1424 & 2769 & 0.9461 & 0.9344 & 0.9651 \\
\hline P2 & 1874 & 1494 & 2959 & 0.9493 & 0.9373 & 0.9673 \\
\hline P3 & 2050 & 1814 & 3336 & 0.9535 & 0.9477 & 0.9709 \\
\hline P4 & 2510 & 2430 & 3750 & 0.9617 & 0.9605 & 0.9740 \\
\hline P5 & 2984 & 2607 & 4068 & 0.9676 & 0.9631 & 0.9760 \\
\hline
\end{tabular}

The results in Table 2 also show the effect of $\mathrm{pH}$ of buffer solution on the equilibrium swelling $\left(S_{e q}\right)$ of hydrogel samples. Values of $S_{e q}$ of AA/AAm/DMAm hydrogels in buffer solution of $\mathrm{pH} 8.0$ is found to be significantly more in comparison to their equilibrium swelling in buffer solution of $\mathrm{pH} 4.0$ and distilled water. It is well known that the swelling of hydrogel is induced by the electrostatic repulsion of the ionic charges of its network. Under acidic pHs $(\leq 4)$, most of the carboxylate anions are protonated, so the main anion-anion repulsive forces are eliminated and consequently swelling values are decreased. Besides, there exist H-bonding interactions between carboxylic groups of acrylic acid and amide groups of acrylamide. These H-bonding interactions result in the formation of a compact or tight structure which does not permit much movement of polymeric chains within the hydrogel network, which lead to minimum swelling of hydrogel. As the $\mathrm{pH}$ of the swelling medium increased, the ionization of the carboxylic acid groups of the gel occurred. That resulted in a more hydrophilic polymer network and contributed to the higher water absorption as the $\mathrm{pH}$ increased.

\subsection{Equilibrium Water Content}

Values of the equilibrium water content (EWC) of all the prepared hydrogel samples were estimated using equation (3) and were tabulated in Table 2. The data in Table 2 showed that values of the EWC of AA/AAm/DMAm hydrogels range from 0.9461-0.9676 in distilled water, 0.9344-0.9631 at $\mathrm{pH} 4$ and $0.9651-0.9760$ at $\mathrm{pH}$ 8. Generally, it is seen that an increasing by the adding of DMAm. Here, the main effect is the hydrophilic character of DMAm groups.

\subsection{Swelling Kinetics}

Once the hydrogel is immersed in a penetrating liquid, the penetrant diffuses into the hydrogel network and the hydrogel swells. The solvent migrates into pre-existing voids or dynamically formed spaces between hydrogel chains. Swelling of the hydrogels involves larger segmental motion resulting, ultimately, in increased separation between hydrogels chains. Based on experimental results, Schott [44, 45] has proposed the following model to describe polymer swelling:

$$
\mathrm{t} / \mathrm{S}=\mathrm{A}+\mathrm{Bt}
$$

Where $S$ is the water uptake at time $\mathrm{t}, \mathrm{B}=1 / S_{e q}$ is the inverse of maximum or equilibrium swelling, $\mathrm{A}=1 / k_{s} S_{\text {eq }}^{2}$ is the reciprocal of the initial swelling rate of the hydrogel material and $k_{s}$ is the swelling rate constant. The final form of equation will be as follows.

$$
t / s=1 / k_{s} S_{e q}^{2}+1 / S_{e q} t
$$

\begin{tabular}{|c|c|c|c|c|c|c|c|c|c|}
\hline \multirow{2}{*}{ Sample } & \multicolumn{3}{|c|}{${ }^{a} S_{e q}$} & \multicolumn{3}{|c|}{${ }^{b} K_{s} \times 10^{-6}$} & \multicolumn{3}{|c|}{${ }^{c} \boldsymbol{K}_{\text {is }}$} \\
\hline & DW & $\mathrm{pH}=4$ & $\mathrm{pH}=8$ & DW & $\mathrm{pH}=4$ & $\mathrm{pH}=8$ & DW & $\mathrm{pH}=4$ & $\mathrm{pH}=8$ \\
\hline $\mathrm{P} 1$ & 2096 & 1628 & 3087 & 2.17 & 3.67 & 2.50 & 9.54 & 9.74 & 23.83 \\
\hline $\mathrm{P} 2$ & 2109 & 1622 & 3173 & 3.17 & 5.78 & 3.60 & 14.08 & 15.21 & 36.24 \\
\hline P3 & 2517 & 2146 & 3725 & 1.52 & 2.17 & 2.08 & 9.61 & 9.99 & 28.85 \\
\hline P4 & 2767 & 2649 & 3949 & 2.62 & 3.89 & 3.84 & 20.09 & 27.3 & 59.85 \\
\hline P5 & 3175 & 2776 & 4317 & 4.14 & 4.51 & 3.03 & 41.75 & 34.78 & 56.45 \\
\hline
\end{tabular}

Table 3. Swelling kinetics parameters of AA/AAm/DMAm hydrogels.

a Theoretical equilibrium swelling; $\mathrm{g}_{\text {water }} / \mathrm{g}_{\mathrm{gel}}$.

${ }^{\mathrm{b}}$ Swelling rate constant $\left(\mathrm{g}_{\mathrm{gel}} / \mathrm{g}_{\mathrm{water}}\right) / \mathrm{min}$.

${ }^{\mathrm{c}}$ Initial swelling rate, $\mathrm{r}(\mathrm{dS} / \mathrm{dt})_{0} ;\left(\mathrm{g}_{\text {water }} / \mathrm{g}_{\mathrm{gel}}\right) / \mathrm{min}$.

The swelling kinetics curves are shown in Figure 5(a-c) by means of Eq. (10), where $t / S$ is plotted against time t to give a straight line with good correlation coefficients for swelling results. From the slope and intercept of lines of Figure 5(a-c), values of swelling rate constant $\left(k_{s}\right)$, the theoretical equilibrium swelling $\left(S_{e q}\right)$ and the initial swelling rate $\left(k_{i s}\right)$ were calculated and the results are given in Table 3.

As shown in Table 3, the values of theoretical swelling equilibrium $S_{e q}$ are similar to the swelling results $\% S_{e q}$ presented in Table 2. Thus it can be concluded from these results that the swelling process is greatly affected by the chemical structure of the monomer repeat units in the polymeric network. Again, the initial swelling rate of AA/AAm/DMAm hydrogel systems is changed with DMAm content. This may be plausible since the hydrophilicity of the network is enhanced with the extent of DMAm groups in structure. 

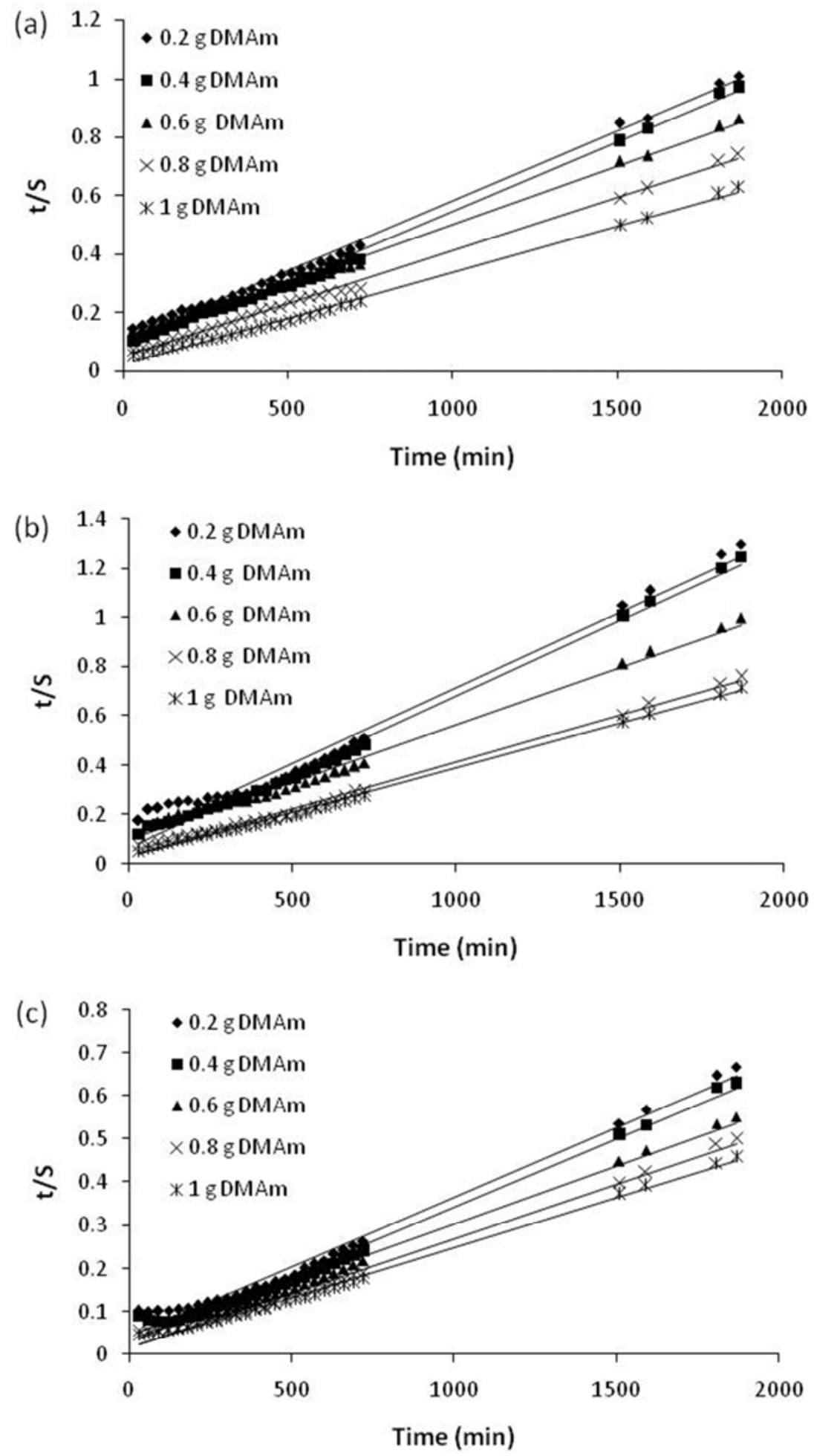

Figure 5. Swelling kinetic curves of AA/AAm/DMAm hydrogel systems as a function of DMAm concentration in (a) distilled water, (b) buffer of pH=4 and (c) buffer of $p H=8$ at $A P E=50 \mathrm{mg}$.

\subsection{Scanning Electron Microscope}

SEM micrographs of AA/AAm/DMAm hydrogel are presented in Figure 6. The SEM studies of hydrogels in presence of water is difficult, therefore the studies were carried out on dried hydrogels. The hydrogel samples were prepared without destroying their microstructure. The SEM photographs indicate that the prepared hydrogels have three dimensional porous structures. Existence of these pores and spongy surface in hydrogels strongly increases the swelling kinetics of the resulted product. It is supposed that these pores are the regions of the water permeation and interaction sites of water molecules with hydrophilic groups of hydrogel. 

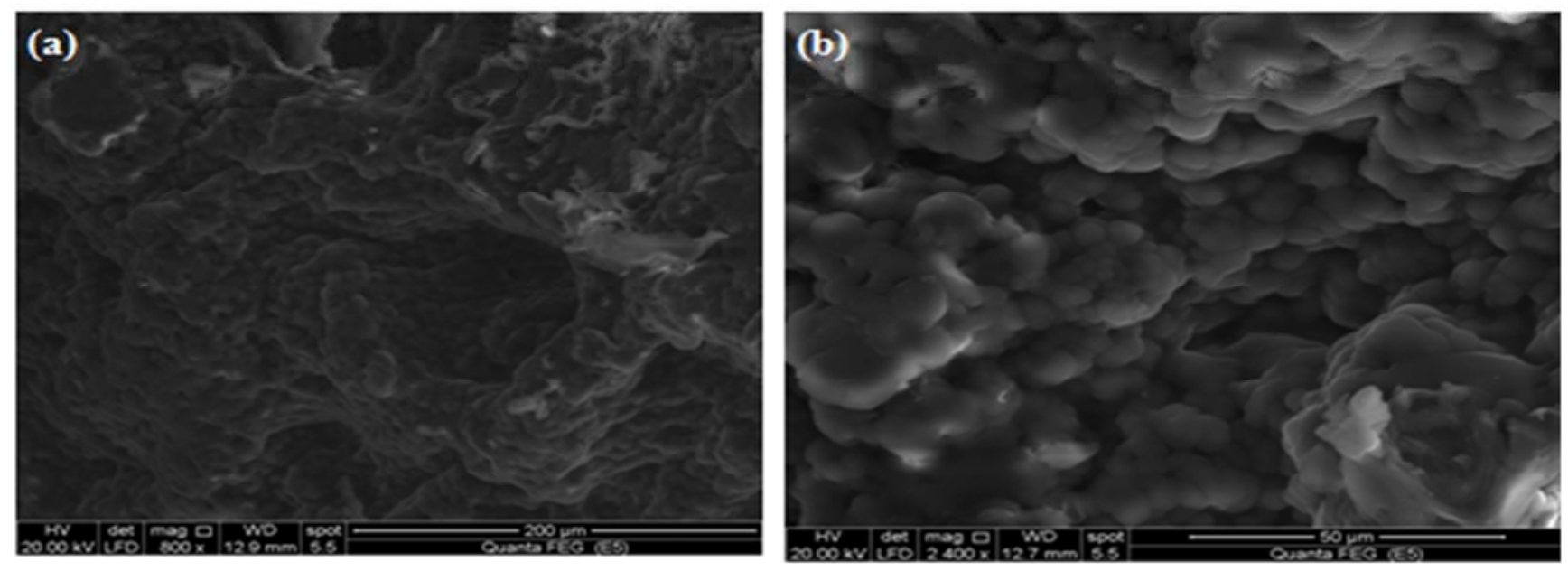

Figure 6. SEM photographs of AA/AAm/DMAm hydrogel at two different magnifications: $a \times 800, b \times 2400$.

\subsection{Thermal Analysis}

Representative TG thermograms of AA/AAm/DMAm hydrogel systems along with derivative thermograms (DTG) curve are shown in Figure 7a and TGA thermograms of all the prepared hydrogel samples are shown in Figure $7 \mathrm{~b}$. The TGA data are given in Table 4 which include the weight loss for all the prepared hydrogels at different temperatures such as $\mathrm{T}_{10}$ (temperature for $10 \%$ weight loss), $\mathrm{T}_{20}$ (temperature for $20 \%$ weight loss), $\mathrm{T}_{50}$ (temperature for $50 \%$ weight loss) and $\mathrm{T}_{\max }$ (temperature for maximum weight loss). It is clearly seen from the figures that weight of the sample continuously decreases as the temperature increases.
TG curves of all the prepared hydrogel samples shows two stages of thermal degradation. The first stage of thermal degradation occurs upto $300^{\circ} \mathrm{C}$ and a weight loss of 22.9$23.7 \%$ was observed. The weight loss in the first stage of thermal degradation may be due to water desorption and anhydride formation [46]. The second stage of thermal degradation is the major stage of degradation which occurs at $300-450^{\circ} \mathrm{C}$ and a weight loss of $63.7-65.1 \%$ for AA/AAm/DMAm hydrogel systems was observed. This may due to the successive cleaving of the backbone of the polymeric hydrogels [46]. The weight loss was nearly constant when temperatures were higher than $450^{\circ} \mathrm{C}$.

Table 4. TGA data of the prepared hydrogels.

\begin{tabular}{|c|c|c|c|c|c|c|c|c|c|c|c|}
\hline \multirow{2}{*}{ Sample } & \multicolumn{5}{|c|}{$\%$ Weight loss at various temperature $\left({ }^{\circ} \mathrm{C}\right)$} & \multirow{2}{*}{$\begin{array}{c}\% \text { wt. loss } \\
300-450\left({ }^{\circ} \mathrm{C}\right)\end{array}$} & \multirow{2}{*}{$\mathrm{T}_{10}\left({ }^{\circ} \mathrm{C}\right)$} & \multirow{2}{*}{$\mathrm{T}_{20}\left({ }^{\circ} \mathrm{C}\right)$} & \multirow{2}{*}{$\mathbf{T}_{50}\left({ }^{\circ} \mathrm{C}\right)$} & \multicolumn{2}{|c|}{$\mathbf{T}_{\text {Max }}\left({ }^{\circ} \mathbf{C}\right)$} \\
\hline & 200 & 300 & 400 & 500 & 600 & & & & & StageI & StageII \\
\hline P1 & 11.6 & 22.9 & 71.1 & 88.8 & 89.9 & 63.7 & 189 & 257 & 379 & 207 & 382 \\
\hline P2 & 11.4 & 23.6 & 72.3 & 93.4 & 94.5 & 67.7 & 192 & 255 & 380 & 205 & 390 \\
\hline P3 & 10.9 & 22.7 & 67.9 & 91.4 & 92.3 & 66.5 & 194 & 267 & 384 & 209 & 392 \\
\hline P4 & 10.8 & 22.9 & 68.3 & 89.3 & 90.3 & 64.3 & 195 & 265 & 382 & 212 & 387 \\
\hline P5 & 11.0 & 23.7 & 68.5 & 90.9 & 91.9 & 65.1 & 193 & 263 & 382 & 210 & 389 \\
\hline
\end{tabular}
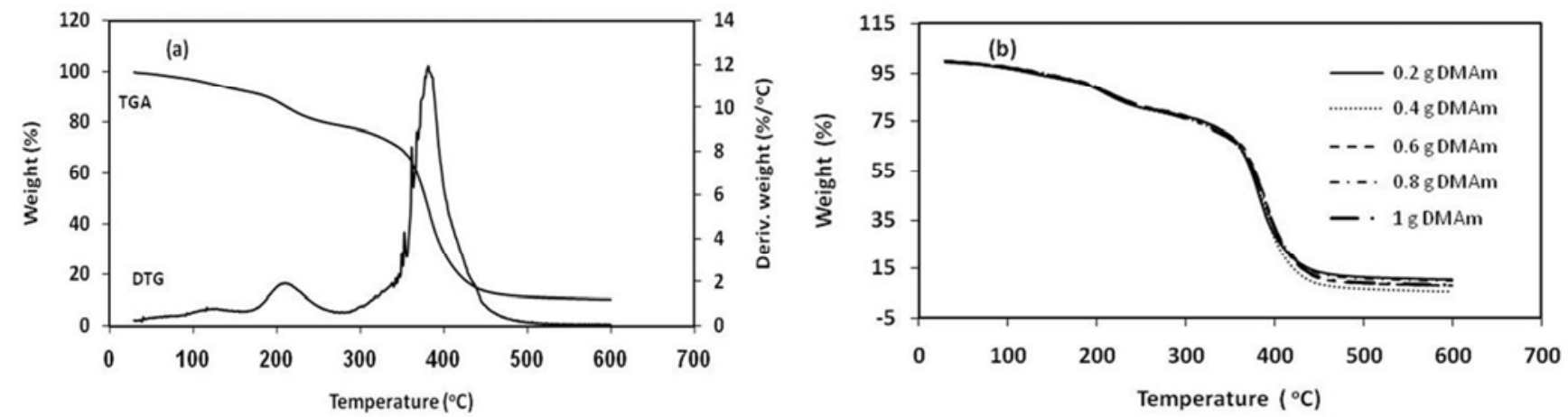

Figure 7. (a) Representative TGA and DTG of AA/AAm/DMAm hydrogel in inert atmosphere and (b)TGA curves of AA/AAm/DMAm hydrogels in inert atmosphere.

\subsection{Dye Adsorption Studies of the Prepared Hydrogels}

Out of the prepared hydrogel samples, P5 sample, which shows higher swelling capacity, was chosen for the adsorption of methylene blue cationic dye from aqueous solutions. 


\subsubsection{Effect of Contact Time}

The effect of contact time on the adsorption of MB onto the prepared hydrogel at an initial concentration of $100 \mathrm{ppm}$ from 0 to $720 \mathrm{~min}$ was investigated to identify the rate of dye removal. As depicted in Figure 8 the adsorption increases with the increasing contact time and rapid adsorption of $\mathrm{MB}$ was observed during the initial $200 \mathrm{~min}$. The amount of MB adsorbed increased rapidly in the early stage and then increased more slowly over extended periods, gradually approaching adsorption equilibrium. This is due to availability of active binding sites on the sorbent at the initial stage. With gradual occupancy of binding sites, the sorption became slower in the later stage [47]. A contact time of $8 \mathrm{~h}$ was sufficient to reach equilibrium. Therefore sorption experiments were conducted for 8 hours.

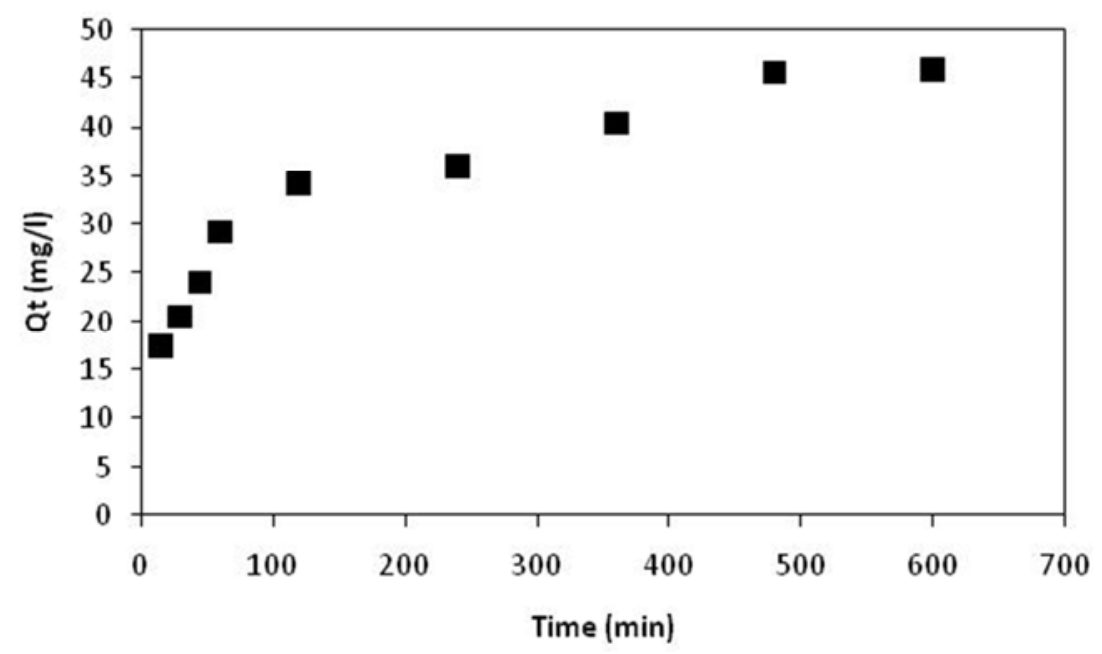

Figure 8. Effect of contact time on dye adsorption $\left[C_{o}=100 \mathrm{mg} / \mathrm{L}\right.$ and $\left.\mathrm{V}=10 \mathrm{~mL}\right]$.

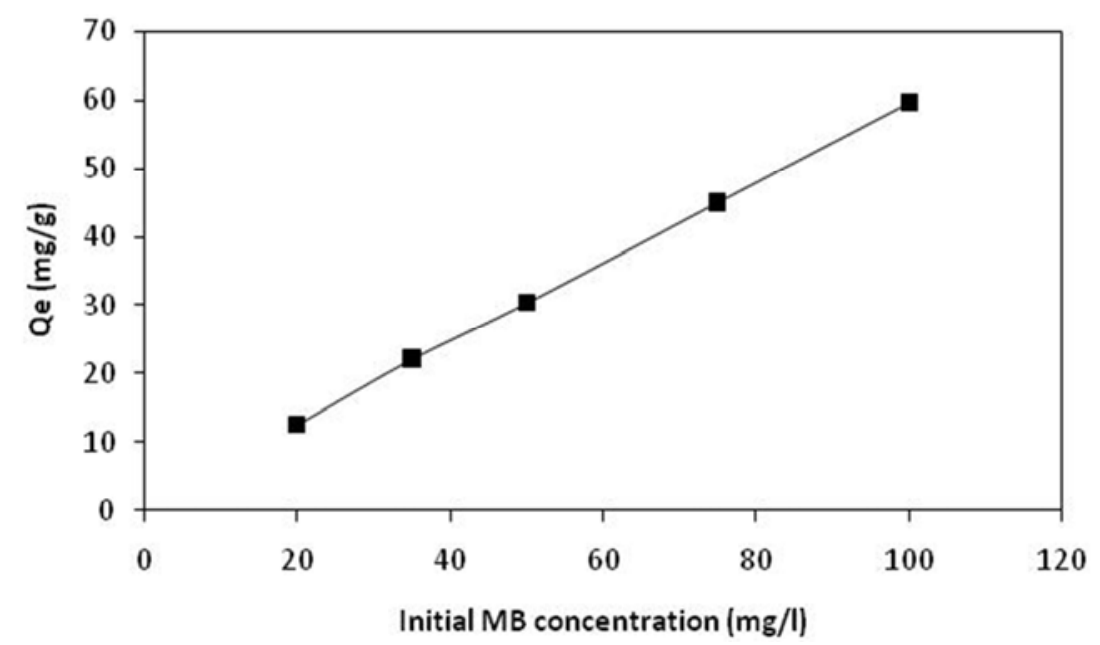

Figure 9. Effect of initial dye concentration ( $\mathrm{MB}$ concentrations $=20-100 \mathrm{mg} / \mathrm{L}, \mathrm{V}=10 \mathrm{~mL}$ and $\mathrm{t}_{\text {eq }}=480 \mathrm{~min}$ ).

\subsubsection{Effect of Initial Dye Concentration}

The effect of initial MB concentrations on adsorption by the prepared hydrogels is depicted in Figure 9. It is evident from the figure that the amount of dye adsorbed $Q_{e}$ increased when the initial concentration was increased from 20 to 100 $m g L^{-1}$. These results suggest that the initial dye concentration is an important factor that determines the efficiency of the adsorption process. The lowest amount of dye adsorbed at lower initial dye concentration may be explained by unsaturated adsorption due to the presence of remaining free adsorption sites.

\subsubsection{Effect of $\mathrm{pH}$}

The initial $\mathrm{pH}$ of the dye solution is an important factor that determines the adsorption behavior. This dependence is due to variation of the surface properties with the $\mathrm{pH}$. These properties include surface charge, chemistry, and number of active sites. The dye adsorption by hydrogels may be explicated by adsorption transport mechanism into swollen polymer networks. The higher water content and porous structure networks allow for solute diffusion through the hydrogel structure. When a hydrogel is dipped in an aqueous medium, it begins to absorb water, resulting in considerably changes of its polymer structure. The dye molecules, upon contact with water, may or may not penetrate into hydrogel depending on established interactions between dye molecules and polymer chains. Effect of $\mathrm{pH}$ on adsorption was studied using $100 \mathrm{mg} \mathrm{L}^{-1}$ dye concentration, $\mathrm{pH} 3,4,7$ and 8 at $25^{\circ} \mathrm{C}$. 
The results shown in Figure 10 indicate that the lowest dye adsorption was recorded at $\mathrm{pH} 3$. The equilibrium adsorption $\left(Q_{e}\right)$ was found to increase with increasing $\mathrm{pH}$. Lower adsorption of $\mathrm{MB}$ at acidic $\mathrm{pH}$ is probably due to the presence of excess $\mathrm{H}^{+}$ions competing with the cation groups on the dye for adsorptionsites. At higher $\mathrm{pH}$, the surface of the hydrogel particles may get negatively charged, which enhances the positively charged dye cations through electrostatic forces of attraction [48, 49]. This can be explained as follow: At higher $\mathrm{pH}$, the carboxylic groups
$\mathrm{COOH}$ present in the hydrogel dissociate to form $\mathrm{COO}^{-}$, increasing the number of fixed ionized groups. This generates electrostatic repulsion forces among the adjacent ionized groups of polymer networks, inducing an expansion of the polymer chains within the hydrogel structure. In this logic, the formation of an ionic complex between the $\mathrm{MB}$ molecules and the hydrogel networks is provided, increasing the dye removal. These interactions occur more precisely between the dye imines groups and the charged groups of the polymer networks.

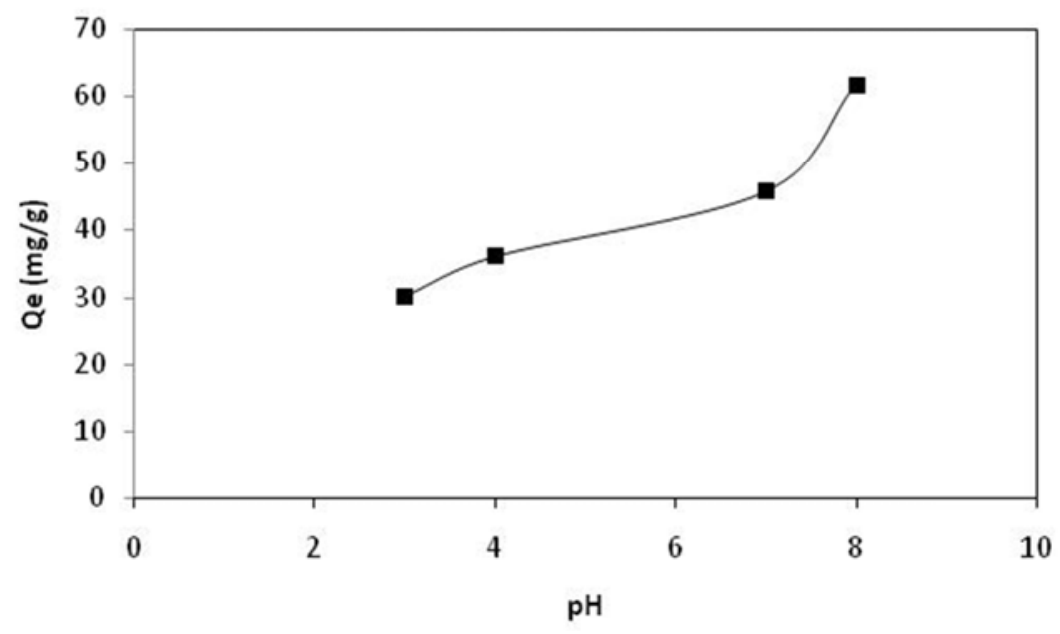

Figure 10. Effect of $\mathrm{pH}$ on $\mathrm{MB}$ removal (MB concentration $=100 \mathrm{mg} / \mathrm{L}$, volume of sample $=10 \mathrm{~mL}$ and equilibrium time $=480 \mathrm{~min}$ ).

\subsubsection{Sorption Kinetics}

In this study, the pseudo-first-order equation and pseudosecond-order equation were used to describe the adsorption of $\mathrm{MB}$ on the prepared hydrogels. The pseudo-first-order kinetic model was suggested by Lagergren [50] for the adsorption of solid/ liquid systems. Values of $\ln \left(Q_{e}-Q_{t}\right)$ and $t / Q_{t}$ were calculated using the equations described in the experimental section. Linear plots of $\ln \left(Q_{e}-Q_{t}\right)$ and $t / Q_{t}$ against $t$ were constructed and used for calculating the kinetic parameters (Figure 11). The calculated kinetic parameters are shown in Table 5. It can be seen from Figure 11 that the Pseudo-second-order kinetic model gave the best fitting of the kinetic data. Using the calculated kinetic models parameters (Table 5), the equilibrium adsorption amount

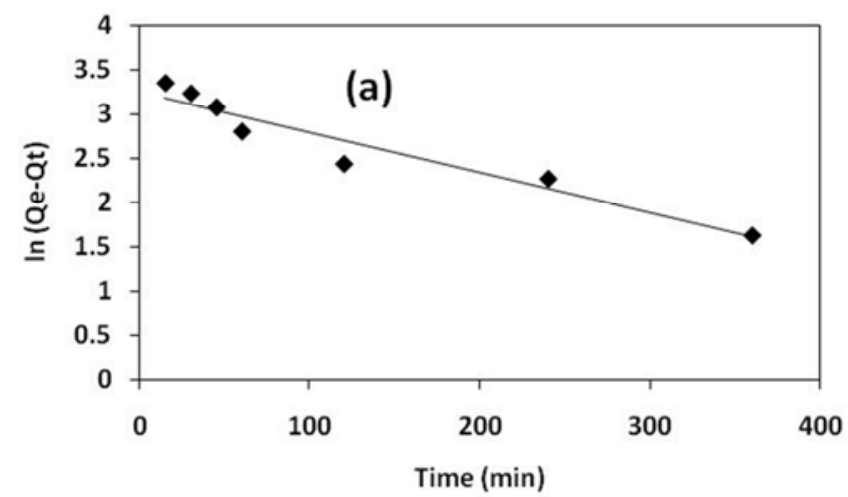

predicted by Pseudo-second-order kinetic model $\left(Q_{e, \text { calc }}\right)$ is very close to the measured value $\left(Q_{e, \text { exp }}\right)$, and the correlation coefficient $R^{2}$ is more than 0.995 . These results suggest that the pseudo-second-order kinetic model closely describes the sorption process of $\mathrm{MB}$ on the prepared hydrogel. It implies the adsorption process is probably a chemical process [51]. And the chemisorption could be rate limiting in the sorption step involving ion exchange of sorbent and sorbate [37]. The correlation coefficients $\left(R^{2}\right)$ for the pseudo first- order kinetic model are lowest in comparison to the values obtained for the pseudo-second-order kinetic model. Moreover, a large difference between $\mathrm{Q}_{\mathrm{e}, \text { calc }}$ and $\mathrm{Q}_{\mathrm{e}, \exp }$ was observed, indicating a poor pseudo-first-order fit to the experimental data.

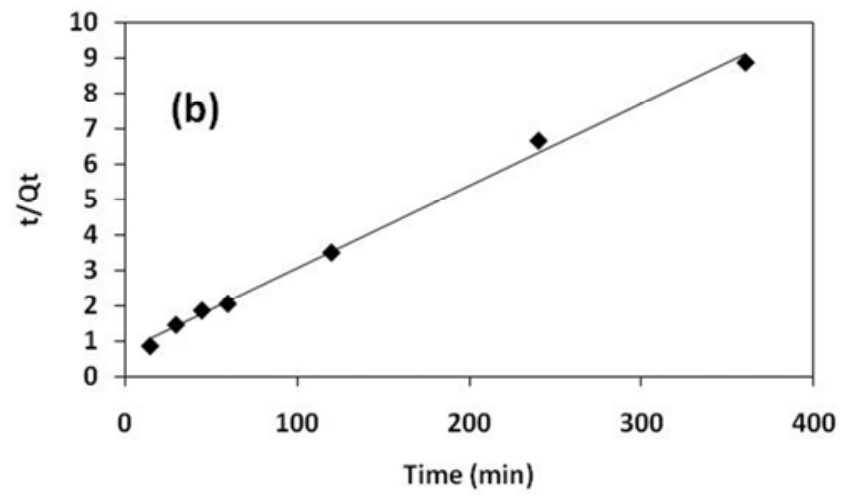

Figure 11. Adsorption kinetics of $M B$ onto AA/AAm/DMAm according to (a) Pseudo first order model (b) Pseudo second order model $/ C_{o}=100 \mathrm{mg} / L$, pH=7 and $\left.T=25^{\circ} \mathrm{C}\right]$. 
Table 5. Adsorption kinetic parameters for MB adsorption on the hydrogels.

\begin{tabular}{|c|c|c|c|c|c|c|c|}
\hline \multirow{2}{*}{ Sample } & \multicolumn{3}{|c|}{ Pseudo-First-Order } & \multicolumn{3}{|c|}{ Pseudo-Second-Order } & \multirow{2}{*}{$\begin{array}{l}\text { Exp. } \\
Q_{e}(m g / g)\end{array}$} \\
\hline & $k_{1}\left(\min ^{-1}\right)$ & $Q_{\mathrm{e}}(\mathrm{mg} / \mathrm{g})$ & $\mathbf{R}^{2}$ & $k_{2}\left(g g^{-1} \min ^{-1}\right)$ & $Q_{\mathrm{e}}(\mathrm{mg} / \mathrm{g})$ & $\mathbf{R}^{2}$ & \\
\hline AA/AAm/DMAm & $4.55 \times 10^{-3}$ & 25.68 & 0.930 & $5.1 \times 10^{-4}$ & 47.07 & 0.995 & 45.7 \\
\hline
\end{tabular}

\subsubsection{Adsorption Isotherms}

The adsorption isotherms are important for description how the molecules of adsorbate distribute between the liquid phase and the solid phase when the adsorption process reaches an equilibrium state. The experimental data on the effect of initial MB concentrations on adsorption by the prepared hydrogels (see Figure 12) were fitted to Langmuir and Freundlich models, which were obtained by plotting $C_{e} / Q e$ versus $C_{e}$ and $\log Q_{e}$ versus $\log C_{e}$, respectively. All isotherm model parameters are presented in Table 6 .

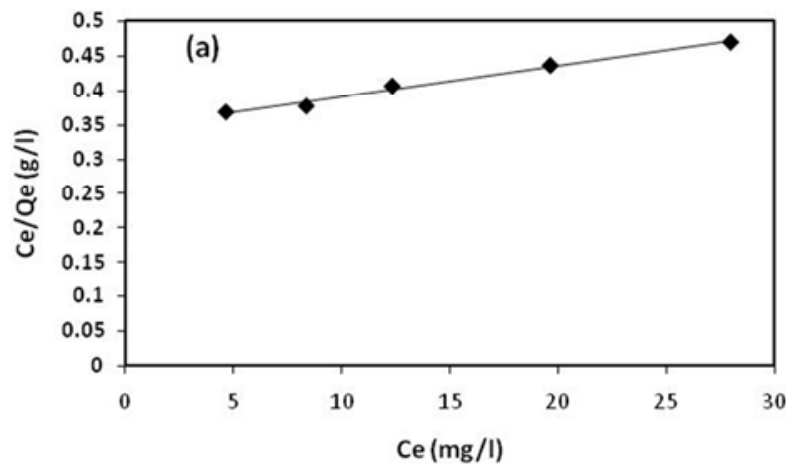

It can be seen that the correlation coefficient $\left(R^{2}\right)$ of Freundlich isotherms is 0.998 ; however, $R^{2}$ values of the Langmuir isotherms are less than those of Freundlich isotherms. These differences in correlation coefficients indicate that the adsorption of $\mathrm{MB}$ on the prepared hydrogel followed the Freundlich model more closely than it followed the Langmuir model. This result suggests that binding of MB occurs on the heterogeneous surface of the hydrogel by multilayer adsorption process.

Figure 12. Adsorption isotherms of $M B$ onto AA/AAm/DMAm according to (a) Langmuir model (b) Freundlich model[ $\left.C_{o}=100 \mathrm{mg} / \mathrm{L}, \mathrm{pH}=7 \mathrm{and} T=25^{\circ} \mathrm{C}\right]$.

Table 6. Adsorption isotherm parameters for $M B$ adsorption on the hydrogels.

\begin{tabular}{|c|c|c|c|c|c|c|}
\hline \multirow{2}{*}{ Sample } & \multicolumn{3}{|c|}{ Langmuir model } & \multicolumn{3}{|c|}{ Freundlich model } \\
\hline & $\mathbf{K}_{\mathbf{L}}$ & $Q_{m}(m g / g)$ & $\mathbf{R}^{2}$ & $\mathbf{K}_{\mathbf{f}}$ & $\mathbf{n}$ & $\mathbf{R}^{2}$ \\
\hline AA/AAm/DMAm & 0.012936 & 223.2031 & 0.989 & 3.45295517 & 1.16176352 & 0.998 \\
\hline
\end{tabular}

\section{Conclusion}

In this study, AA/AAm/DMAm hydrogels were prepared by free radical polymerization in solution. Hydrogels were swollen to equilibrium in water. It was found that the adsorption capacity of the prepared hydrogels increases by increasing the DMAm content. Hydrogel systems swelled in the range $1757-2984 \%$ in distilled water, $1424-2607 \%$ at $\mathrm{pH}$ 4 and $2769-4068 \%$ at $\mathrm{pH} 8$. The values of EWCs were found to be in the range 0.9461-0.9676 in distilled water, 0.93440.9631 at $\mathrm{pH} 4$ and $0.9651-0.9760$ at $\mathrm{pH}$ 8. This result showed that AA/AAm/DMAm hydrogels would be used as a new material (such as a biomaterial) on some biomedical applications, because EWCs was bigger than the percent water content value of the body about 0.60 . The hydrogel was also used in adsorption of the MB dye from aqueous solutions. It was found that the adsorption kinetics of hydrogels followed a pseudo-second-order model. Equilibrium isotherms were analyzed using the Langmuir and Freundlich isotherms. It was seen that the Freundlich model fits the adsorption data better than the Langmuir model. Therefore, AA/AAm/DMAm can be used as effective adsorbents for the removalof MB from wastewaters.

\section{Acknowledgement}

Support of this study by the department of applied chemistry, Al-Azhar University, Cairo, Egypt, is gratefully appreciated.

\section{References}

[1] G. Crini, "Recent developments in polysaccharide-based materials used as adsorbents in wastewater treatment" Prog. Polym. Sci., 30 (2005) 38-70.

[2] P. K. Dutta, "An overview of textile pollution and its remedy" Indian J. Environ. Prot., 14 (1994) 443-446.

[3] K. C. Chen, J. Y. Wu, C. C. Huang, Y. M. Liang, S. C. J. Hwang, "Decolorization of azo dye using PVA-immobilized microorganisms" J. Biotechnol., 101 (2003) 241-252. 
[4] R. Gong, Y. Ding, M. Li, C. Yang, H. Liu, Y. Sun, "Utilization of powdered peanut hull as biosorbent for removal of anionic dyes from aqueous solution" Dyes and Pigments, 64 (2005) 187-192.

[5] D. Ghosh, K. G. Bhattacharyya, "Adsorption of methylene blue on kaolinite" Appl. Clay Sci. 20 (2002) 295-300.

[6] E. Guibal, J. Roussy, "Coagulation and flocculation of dyecontaining solutions using a biopolymer (Chitosan)" Reac. Funct. Polym., 67 (2007) 33-42.

[7] K. M. Majewska-Nowak, "Application of ceramic membranes for the separation of dye particles" Desalination, 254 (2010) 185-191.

[8] E. S. Z. El-Ashtoukhy, N. K. Amin, "Removal of acid green dye 50 from wastewater by anodic oxidation and electrocoagulation-A comparative study" J. Hazard. Mater., 179 (2010) 113-119.

[9] M. Muthukumar, N. Selvakumar, "Studies on the effect of inorganic salts on decolouration of acid dye effluents by ozonation" Dyes and Pigments, 62 (2004) 221-228.

[10] A. Alinsafi, M. Khemis, M. N. Pons, J. P. Leclerc, A. Yaacoubi, A. Benhammou, A. Nejmeddine, "Electrocoagulation of reactive textile dyes and textile wastewater" Chem. Eng. Process., 44 (2005) 461-470.

[11] H. Han, W. Wei, Z. Jiang, J. Lu, J. Zhu, J. Xie, "Removal of cationic dyes from aqueous solution by adsorption onto hydrophobic/hydrophilic silica aerogel" Colloids Surf., A: Physicochemical and Engineering Aspects, 509 (2016) 539549.

[12] R. Coskun, "Removal of cationic dye from aqueous solution by adsorption onto crosslinkedpoly(4-vinylpyridine/crotonic acid) and its N-oxide derivative" Polym. Bull., 67 (2011) 125140.

[13] A. Salama, N. Shukry, M. El-Sakhawy, "Carboxymethyl cellulose-g-poly (2-(dimethylamino) ethyl methacrylate) hydrogel as adsorbent for dye removal" Int. J. Biol. Macromol., 73 (2015) 72-75.

[14] V. P. Vesna, Z. P. Madzarevic, T. Volkov-Husovic, S. J. Velickovic, "Poly(methacrylic acid) based hydrogels as sorbents for removal of cationic dye basic yellow 28: Kinetics, equilibrium study and image analysis" Chemical Eng. J.,217 (2013) 192-204.

[15] R. Bhattacharyya, S. K. Ray,"Enhanced adsorption of synthetic dyes from aqueous solution by a semiinterpenetrating network hydrogel based on starch" J.Indus. Eng. Chem., 20 (2014) 3714-3725.

[16] H. Hosseinzadeh, N. Khoshnood" Removal of cationic dyes by poly(AA-co-AMPS)/ montmorillonitenanocomposite hydrogel"Desalin. Water Treat., 57 (2015) 1-12.

[17] A. S. Hoffman,"Hydrogels for biomedical applications" Adv. Drug Deliv. Rev., 54 (2002) 3-12.

[18] D. M. García, J. L. Escobar, Y. Noa, N. Bada, E. Hernáez, Katime,"Timolol maleate release from $\mathrm{pH}$-sensible poly(2hydroxyethyl methacrylate-co-methacrylic acid) hydrogels" Euro.Polym.J., 40 (2004) 1683-1690.

[19] Z. Li, Y. Wang, N. Wu, Q. Chen, K. Wu, "Removal of heavy metal ions from wastewater by a novel HEA/AMPS copolymer hydrogel: preparation, characterization, and mechanism" Environ. Sci. Pollut. Res., 20 (2013) 1511-1525.

[20] B. Hui, L. Ye, "Structure of polyvinyl alcohol-g-acrylic acid2-acrylamido-2-methyl-1-propanesulfonic acid hydrogel and adsorption mechanism for advanced $\mathrm{Pb}(\mathrm{II})$ removal" J. Ind. Eng. Chem., 35 (2016) 309-317.

[21] N. Kanarat, S. Nantarat, W. Chinanat, M. Robert,"Design and Preparation of AMPS-Based Hydrogels for Biomedical Use as Wound Dressings" Chiang Mai. J. Sci., 34 (2007) 183-189.

[22] H. Hosseinzadeh,"Synthesis and swelling properties of a poly (vinyl alcohol)-based superabsorbing hydrogel" Curr. Chem. Lett., 2 (2013) 153-158.

[23] S. Thakur, S. Pandey, O. A. Arotiba, "Development of a sodium alginate-based organic/inorganic superabsorbent composite hydrogel for adsorption of methylene blue" Carbohydr. Polym., 153 (2016) 34-46.

[24] R. Fang, W. He, H. Xue, W. Chen, "Synthesis and characterization of a high-capacity cationic hydrogel adsorbent and its application in the removal of Acid Black 1 from aqueous solution" Reac.Funct. Polym., 102 (2016) 1-10.

[25] K. H. Hong, Y. Jeon, D. J. Chung, J. Kim, "Drug Release Characteristics of Modified PHEMA Hydrogel Containing Thermo-responsive Pluronic Copolymer" Macromol.Res., 18(2010) 204-207.

[26] S. Atta, S. Khaliq, A. Islamb, I. Javeria, T. Jamil, M. M. Athar, M. I. Shafiq, Abdul Ghaffar,"Injectable biopolymer based hydrogels for drug delivery applications" Intern. J. Biological Macromol., 80 (2015) 240-245.

[27] H. El-Hamshary, "Synthesis and water sorption studies of $\mathrm{pH}$ sensitive poly(acrylamide-co-itaconic acid) hydrogels" Euro. Polym.J., 43 (2007) 4830-4838.

[28] Y. M. Mohan, P. S. K. Murthy, K. M. Raju,"Synthesis, characterization and effect of reaction parameters on swelling properties of acrylamide-sodium methacrylate superabsorbent copolymers"Reac. Funct.Polym., 63 (2005) 11-26.

[29] N. Gundogan, O. Okay, W. Oppermann, "Swelling, Elasticity and Spatial Inhomogeneity of Poly(N,N-dimethylacrylamide) Hydrogels Formed at Various Polymer Concentrations"Macromol. Chem. Phys., 205 (2004) 814-823.

[30] T. Caykara, I. Akcakaya, "Synthesis and network structure of ionic poly(N,N-dimethylacrylamide-co-acrylamide) hydrogels: Comparison of swelling degree with theory"Euro.Polym. J., 42 (2006) 1437-1445.

[31] A. Thakur, R. k. Wanchoo, P. Singh, "Structural Parameters and Swelling Behavior of $\mathrm{pH}$ Sensitive Poly(acrylamide-coacrylic acid) Hydrogels" Chem. Biochem. Eng. Q., 25 (2011) 181-194.

[32] H. Mittal, R. Jindal, B. S. Kaithb, A. Maity, S. S. Ray, "Flocculation and adsorption properties of biodegradable gumghatti-grafted poly (acrylamide-co-methacrylic acid) hydrogels" Carbohydr.Polym., 115 (2015) 617-628.

[33] I. Ohmine, T. Tanaka,"Salt effects on the phase transition of ionic gels" J. Chem. Phys. 77 (1982) 5725-5729.

[34] S. Katayama, Y. Hirokawa, T. Tanaka,"Reentrant phase transition in acrylamide-derivative copolymer gels" Macromol., 17 (1984) 2641-2643. 
[35] D. Saraydin, E. Karadă̆, Y. Ișıkver, N. Sahiner, O. Güven, "The Influence of Preparation Methods on the Swelling and Network Properties of Acrylamide Hydrogels with Crosslinkers" J. Macromol. Sci. Part A-Pure Appl. Chem., A 41 (2004) 419-431.

[36] S. J. Lee, S. S. Kim, Y. M. Lee, "Interpenetrating polymer network hydrogels based on poly (ethylene glycol) macromer and chitosan" Carbohydr. Poly., 41 (2000) 197-205.

[37] Y. S. Ho, G. Mckay, "pseudo-second order model for sorption processes" process biochem. 34 (1999) 451-465.

[38] H. Chen, A. Wang, "Adsorption characteristics of $\mathrm{Cu}$ (II) from aqueous solution onto poly (acrylamide)/attapulgite composite" J. Hazard. Mater., 31 (2009) 223.

[39] I. Langmuir, "The adsorption of gases on lane surfaces of glass, mica and platinum" J. Am. Chem. Soc. 40 (1918) 13611403 .

[40] H. M. F. Freundlich, "Over the adsorption in solution" J. Phys. Chem., 57 (1906) 385-470.

[41] S. Reena, S. T. Rajiv, A. K. Nagpal, "Effect of cross-linker and initiator concentration on the swelling behaviour and network parameters of superabsorbent hydrogels based on acrylamide and acrylic acid" Int. J. Plast. Technol., 13 (2009) 22-37.

[42] S. Mohammad, H. Behrouz, "Crosslinked Graft Copolymer of Methacrylic Acid and Gelatin as a Novel Hydrogel with $\mathrm{pH}-$ Responsiveness Properties" Materials 4 (2011) 543-552.

[43] F. A. Hai, H. Abd El-Wahab, A. G. Ibrahim, "Synthesis, characterization, and thermal properties of thiazole containing polymers" Malaysian Polym. J., 9 (2014) 1-9.
[44] H. Schott, "Swelling kinetics of polymers" J. Macromol. Sci. Phys., B31 (1992) 1-9.

[45] J. R. Quintana, N. E. Valderruten, I. Katime, "Synthesis and Swelling Kinetics of Poly (Dimethylaminoethyl acrylate methyl chloride quaternary-co-itaconic acid) Hydrogels" Langmuir, 15 (1999) 4728-4730.

[46] A. El-Hag Ali, H. A. Shawky, H. A. Abd El Rehim, E. A. Hegazy,"Synthesis and characterization of PVP/AAc copolymer hydrogel and its applications in the removal of heavy metals from aqueous solution" Euro.Polym. J., 39 (2003) 2337-2344.

[47] S. M. Nomanbhay, K. Balanisamy, "Removal of heavy metals from industrial wastewater using chitosan coated oil palm shell charcoa" electron. j.biotechnol., 8 (2004) 43-53.

[48] S. Wang, L. Li, H. Wu, Z. H. Zhu,"Unburned carbon as a lowcost adsorbent for treatment of methylene blue-containing wastewater"J. Colloid Interf. Sci., 292 (2005) 336-343.

[49] B. H. Hameed, D. K. Mahmoud, A. L. Ahmed, "Equilibrium modeling and kinetic studies on the adsorption of basic dye by a low-cost adsorbent: Coconut (Cocosnucifera) bunch waste" J. Hazard. Mater., 158 (2008) 65-72.

[50] S. Lagregren, "About the theory of so-called adsorption of soluble substances" Kungl. Sven. Veten. Akad. Handl., 24 (1898) 1-39.

[51] Y. J. Wu, L. J. Zhang, C. L. Gao, J. Y. Ma, X. H. Ma, R. P. Han, "Adsorption of Copper Ions and Methylene Blue in a Single and Binary System on Wheat Straw" J. Chem. Eng. Data., 54 (2009) 3229-3234. 